\title{
Photoluminescence studies of cubic GaN epilayers
}

DOI:

10.1002/pssb.201600733

\section{Document Version}

Accepted author manuscript

Link to publication record in Manchester Research Explorer

\section{Citation for published version (APA):}

Church, S., Hammersley, S., Mitchell, P., M. J. Kappers, Sahonta, S-L., Frentrup, M., Nilsson, D., Ward, J., Shaw, L. J., Wallis, D. J., C. J. Humphreys, R. A. Oliver, Binks, D., \& Dawson, P. (2017). Photoluminescence studies of cubic GaN epilayers. Physica status solidi B-basic solid state physics. https://doi.org/10.1002/pssb.201600733

\section{Published in:}

Physica status solidi B-basic solid state physics

\section{Citing this paper}

Please note that where the full-text provided on Manchester Research Explorer is the Author Accepted Manuscript or Proof version this may differ from the final Published version. If citing, it is advised that you check and use the publisher's definitive version.

\section{General rights}

Copyright and moral rights for the publications made accessible in the Research Explorer are retained by the authors and/or other copyright owners and it is a condition of accessing publications that users recognise and abide by the legal requirements associated with these rights.

\section{Takedown policy}

If you believe that this document breaches copyright please refer to the University of Manchester's Takedown Procedures [http://man.ac.uk/04Y6Bo] or contact uml.scholarlycommunications@manchester.ac.uk providing relevant details, so we can investigate your claim.

\section{OPEN ACCESS}




\title{
Photoluminescence studies of cubic GaN epilayers
}

\author{
S. A. Church ${ }^{*}$, , S. Hammersley ${ }^{1}$, P. W. Mitchell ${ }^{1}$, M. J. Kappers², S. L. Sahonta ${ }^{2}$, M. Frentrup ${ }^{2}$, D. Nilsson ${ }^{3}$, P. \\ J. Ward ${ }^{3}$, L. J. Shaw ${ }^{3}$, D. J. Wallis ${ }^{2}$, C. J. Humphreys ${ }^{2}$, R. A. Oliver ${ }^{2}$, D. J. Binks' ${ }^{1}$, P. Dawson ${ }^{1}$ \\ ${ }^{1}$ School of Physics and Astronomy, Photon Science Institute, University of Manchester, Manchester M13 9PL, United Kingdom \\ ${ }^{2}$ Department of Materials Science and Metallurgy, University of Cambridge, 27 Charles Babbage Road, Cambridge CB3 0FS, United \\ Kingdom \\ ${ }^{3}$ Anvil Semiconductors Ltd., Future Business Centre, King's Hedges Road, Cambridge CB4 2HY, United Kingdom
}

Received XXXX, revised XXXX, accepted XXXX

Published online XXXX

Key words: Cubic GaN, Zincblende GaN, stacking faults, hexagonal inclusions, photoluminescence.

${ }^{*}$ Corresponding author: e-mail stephen.church@manchester.ac.uk

The luminescence properties of cubic GaN films grown upon 3C-SiC/Si (001) substrates by MOCVD were investigated. The spectra show luminescence peaks which are associated with donor bound exciton recombination and donor acceptor pair recombination. A reduced peak energy for the $\mathrm{D}^{0} \mathrm{X}$ emission compared values reported in the literature suggests a tensile-strain-reduced bandgap of approximately $3.27 \mathrm{eV}$, which is consistent with the absorption edge in photoluminescenceexcitation spectroscopy. The presence of hexagonal material introduces a broad emission band at $3.40 \mathrm{eV}$ with a FWHM of $190 \mathrm{meV}$, extending to energies up to $3.60 \mathrm{eV}$. The intensity of this emission scales linearly with excitation power, its peak energy and width remaining unchanged. This band is associated with an absorption edge below $3.70 \mathrm{eV}$ and therefore is not caused by absorption into phase-pure cubic or hexagonal GaN. The photoluminescence lifetimes measured across this band reduce from $0.40 \mathrm{~ns}$ to $0.20 \mathrm{~ns}$ with increasing emission energy. All these observations can be explained by considering a type-II-band alignment adjacent to stacking faults within the cubic GaN.
1 Introduction InGaN/GaN quantum wells (QWs) grown on cubic $\mathrm{GaN}$ are not subject to the strong electric fields perpendicular to the plane of the wells found in conventional QWs grown along the c-axis of hexagonal GaN [1-3]. So, compared with c-plane hexagonal structures, the electron-hole wavefunction overlap is increased, which should lead to an increase in the radiative recombination rate. In addition, since cubic GaN has a smaller bandgap than hexagonal GaN, longer wavelength visible QW emission can be achieved with a comparatively lower indium content. This will reduce the lattice mismatch at the heterointerface and may therefore lead to reduced defect densities in QWs. These two effects are likely to improve the internal quantum efficiency (IQE) of cubic InGaN/GaN QWs, and make them promising active layer candidates for efficient green LEDs [4,5]. However, cubic GaN is ther- modynamically metastable during growth; therefore often a large proportion of the stable hexagonal phase will form in the structure which can negatively impact the structural and luminescence properties of the films [6]. Therefore, detailed study and optimisation of cubic $\mathrm{GaN}$ is an important step towards device development.

3C-SiC/Si (001) substrates have a number of favorable properties which make them well-suited for the epitaxial growth of cubic GaN [1,6-14]. These substrates can be produced with large diameters and are therefore compatible with commercial processing in $\mathrm{Si}$ foundries, providing a clear path to commercialisation of cubic GaN based LEDs. Also, the relatively small lattice mismatch between 3C-SiC and cubic GaN (3.7 \% [15]) has the potential to reduce the strain in the crystal and improve the crystal quality compared with other substrates. 
Here we investigate the effect of hexagonal phase impurities on the photoluminescence (PL) spectra of cubic $\mathrm{GaN}$ grown on $3 \mathrm{C}-\mathrm{SiC} / \mathrm{Si}$ substrates.

2 Experimental Method The cubic GaN studied in this work was epitaxially grown via metal-organic chemical vapour deposition (MOCVD) using a two-step growth method similar to that described by Wei et al [6]. The growth was performed on ca. $1 \times 1$ inch $^{2}$ pieces cut from $100 \mathrm{~mm}$ diameter 3C-SiC/Si (001) substrates. A reference sample (A) was produced upon a substrate with $750 \mu \mathrm{m}$ of $\mathrm{Si}(001)$ and $7.0 \mu \mathrm{m}$ of 3C-SiC, and consisted of a layer of $250 \mathrm{~nm}$ of cubic GaN. X-ray diffraction (XRD) reciprocal space maps reveal a relatively low integrated intensity for the $10 \overline{1} 1$ hexagonal $\mathrm{GaN}$ reflection compared with the symmetric 002 cubic $\mathrm{GaN}$ reflection, indicating that the amount of hexagonal material is around $5 \%$. Sample (B) was produced on a $6.3 \mu \mathrm{m}$ layer of $3 \mathrm{C}-\mathrm{SiC}$ on a $525 \mu \mathrm{m}$ thick Si (001) layer, which contained a $250 \mathrm{~nm}$ cubic $\mathrm{GaN}$ layer, followed by a $10 \mathrm{~nm}$ AlN interlayer, and a $500 \mathrm{~nm}$ layer of $\mathrm{GaN}$ above this. A significantly higher amount of hexagonal GaN in sample (B), around 50\%, was observed in XRD measurements. The phase impurities can also be observed in TEM measurements, such as those shown in Figure 1, which indicate the presence of hexagonal GaN above the interlayer in sample B. This is incorporated as crystal inclusions up to $300 \mathrm{~nm}$ in size and thin planes of hexagonal GaN known as stacking faults (SFs). A $5.0 \mu \mathrm{m}$ layer of c-plane hexagonal $\mathrm{GaN}$ grown upon c-plane sapphire was also studied for comparison, (C).

These samples were mounted upon the cold-finger of a closed-cycle helium cryostat at temperatures between $10 \mathrm{~K}$ and $300 \mathrm{~K}$. Excitation was performed using a CW $40 \mathrm{~mW}$ $\mathrm{HeCd}$ laser emitting at $325 \mathrm{~nm}(3.81 \mathrm{eV})$, focussed to provide excitation densities up to $4000 \mathrm{Wcm}^{-2}$. The $1 / e$ absorption depth of this excitation is approximately $80 \mathrm{~nm}$ $[12,18]$ and the $1 / e$ carrier diffusion length at low temperature is expected to be of a similar magnitude [19]. The number of photoexcited carriers which recombine close to interfaces with the interlayer or substrate is therefore expected to be small; these measurements are most sensitive to the material near the surface of each sample. A comparison of samples A and B would therefore reflect the difference between cubic and mixed-phase GaN. The luminescence was collected by a double-grating spectrometer with $24 \AA$ resolution and detected with a PMT using lock-in amplification techniques. The emission spectra from such a setup is typically influenced by Fabry-Pérot interference, which was reduced by orientating the samples at Brewster's angle, with the unreflected p-polarised light selected by a linear polariser and collected by the spectrometer [20].

Photoluminescence-excitation spectroscopy was performed on samples using a $300 \mathrm{~W}$ Xe lamp, combined with a monochromator, to provide a variable-energy excitation

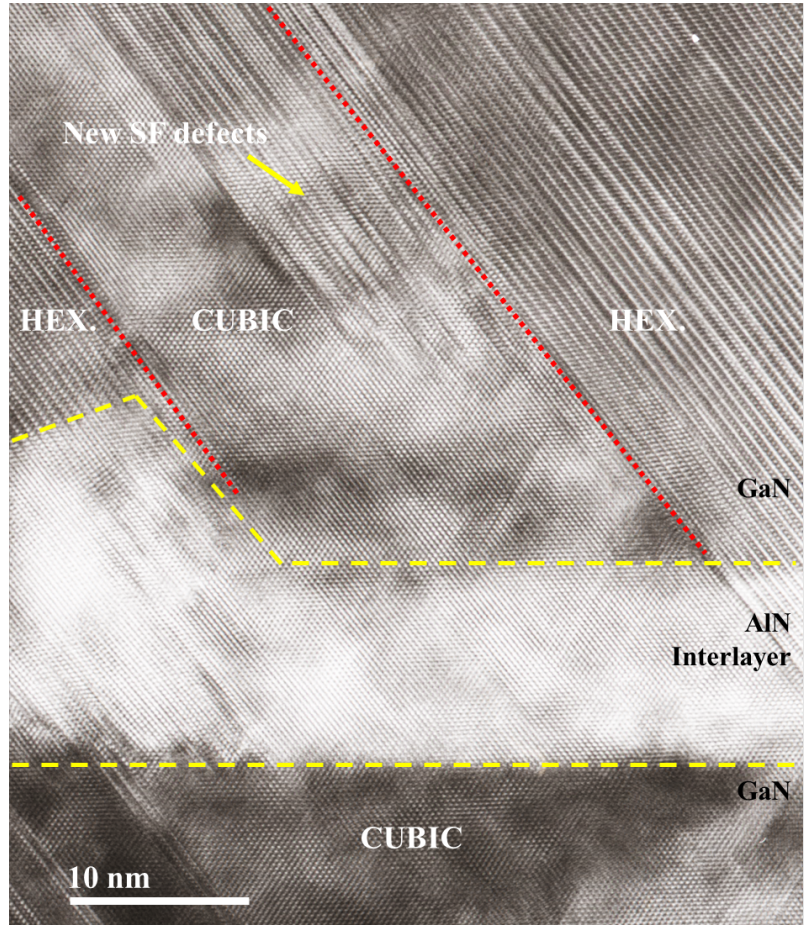

Figure 1 TEM measurement of a small region of sample B, showing the formation of stacking faults and hexagonal inclusions around the AIN interlayer.

source. In this technique, the excitation photon energy is varied whilst monitoring the luminescence intensity at a constant photon energy.

To measure the PL time-decays of the samples, a frequency tripled Ti:sapphire laser was used to produce excitation pulses with a $100 \mathrm{fs}$ duration at a wavelength of $267 \mathrm{~nm}$. Standard time-correlated single-photon counting techniques were used to produce a histogram of the variation of photon counts versus time delay for various detection energies, with a time-resolution of $0.08 \mathrm{~ns}$.

3 Results and Discussion The PL spectra of all samples measured at $10 \mathrm{~K}$ are shown in Figure 2. The bandgap of unstrained hexagonal $\mathrm{GaN}$ at these temperatures is $3.50 \mathrm{eV}$ [21]. Sample C exhibits an intense excitonic peak $(\mathrm{X})$ at $3.48 \mathrm{eV}$, with a full-width at half maximum (FWHM) of $12 \mathrm{meV}$, which is followed by two LO phonon replicas, each separated by $91 \mathrm{meV}$. Broad emission bands are present at $3.00 \mathrm{eV}$ and $2.20 \mathrm{eV}$, each with a FWHM around $400 \mathrm{meV}$, which are the yellow and blue luminescence (YL, BL) bands commonly reported in the literature [22].

In contrast, cubic samples $\mathrm{A}$ and $\mathrm{B}$ show dominant emission peaks at $3.23 \mathrm{eV}$ and $3.24 \mathrm{eV}$ respectively. Photoluminescence-excitation measurements in Figure 3 indicate that the emission is associated with a steep absorption edge between $3.26 \mathrm{eV}$ and $3.27 \mathrm{eV}$. Temperature- 


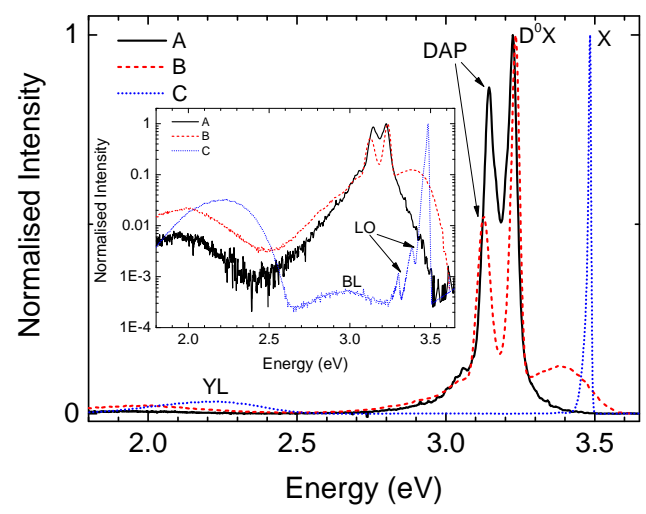

Figure 2 Normalised PL at $10 \mathrm{~K}$ for all samples, measured with an excitation power density of $10 \mathrm{Wcm}^{-2}$. Inset is the same spectra on a semi-log scale to illustrate the blue luminescence and phonon replicas in sample $\mathrm{C}$.

dependent PL measurements show the peak energy initially blueshifts up to $120 \mathrm{~K}$, before redshifting at higher temperatures, as shown for sample B in Figure 4. The peak energy follows a Varshni bandgap temperature dependence above $120 \mathrm{~K}$, with parameters $\alpha=0.538(8) \mathrm{meVK}^{-1}$ and $\beta=300(100) \mathrm{K}$, which are within the expected range for $\mathrm{GaN}$ [21]. This temperature dependence allows us to attribute this feature to recombination of excitons bound to neutral donors $\left(\mathrm{D}^{0} \mathrm{X}\right)$ within the cubic $\mathrm{GaN}$ at low temperature. As the temperature is increased, the bound exci-

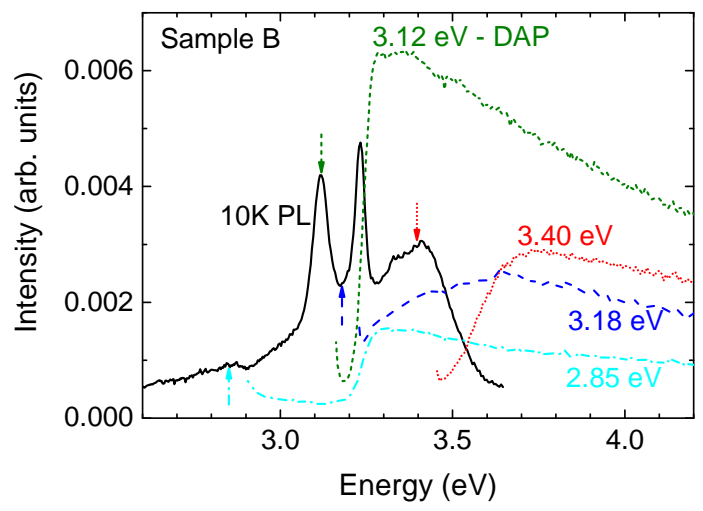

Figure 3 PL spectrum of sample B measured at $10 \mathrm{~K}$ with an excitation energy of $3.81 \mathrm{eV}$ (solid line). $10 \mathrm{~K}$ photoluminescenceexcitation spectra (dot and dash lines), with detection energies of $3.40,3.18,3.12$ and $2.85 \mathrm{eV}$, indicated by arrows, which correspond to the high energy band, between the DAP and $\mathrm{D}^{0} \mathrm{X}$ peaks, the DAP peak and the low intensity band respectively. The increase in photoluminescence-excitation intensity close to the detection energy is caused by the scattered excitation beam.

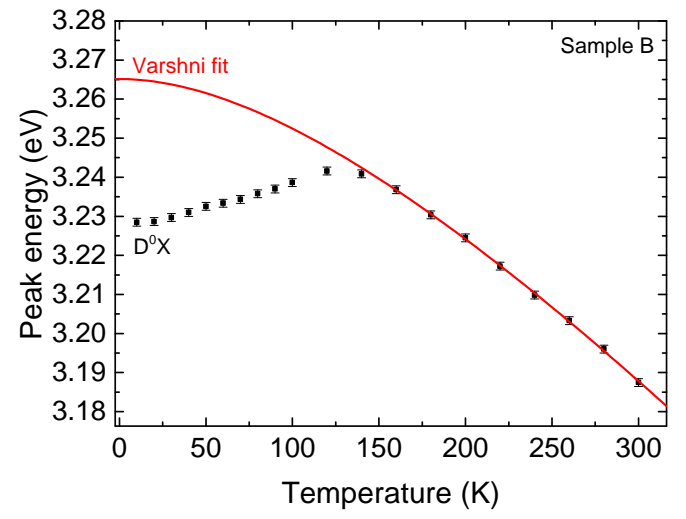

Figure 4 Temperature dependence of the peak energy of the nearband-edge emission for sample B (black). An empirical Varshni fit to measurements above $140 \mathrm{~K}$ is shown (red) and extrapolated to $10 \mathrm{~K}$.

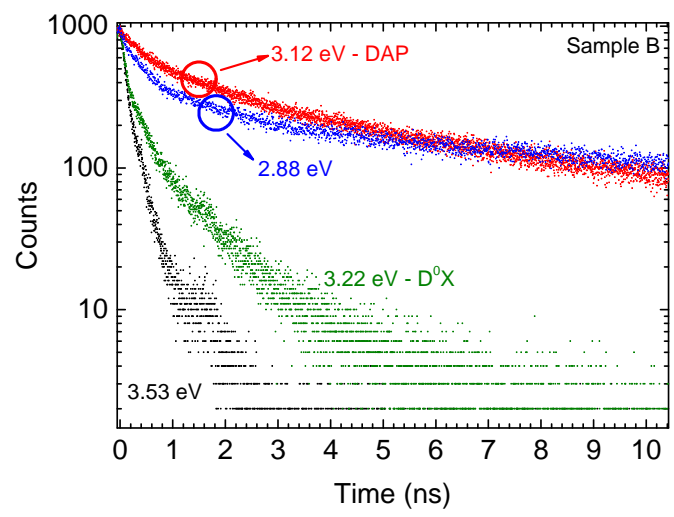

Figure 5 PL time decays for sample B, measured at $10 \mathrm{~K}$. The discontinuity in decays at $1.40 \mathrm{~ns}$ is caused by the system response.

tons are ionised, resulting in recombination of free excitons, causing the resultant blueshift [9]. The assignment is also consistent with the observed PL decay curves, as in Figure 5, which shows that the decay transients of the feature are fast ( $0.17 \mathrm{~ns}$ lifetime) and monoexponential [23] for the first $70 \%$ of the decay. An additional, slower monoexponential component with $0.65 \mathrm{~ns}$ lifetime is present in these decay curves, which may be caused by spectral overlap with the wing of the high energy band seen in Figure 2 for sample $\mathrm{B}$, which will be discussed later.

It is of note that the peak energy of the $\mathrm{D}^{0} \mathrm{X}$ features are lower than reported in the literature by between $0.03 \mathrm{eV}$ and $0.04 \mathrm{eV}[7,9,11,12,23-28]$. This may be a result of a reduced bandgap due to tensile strain in the GaN [23], which lies between $0.5 \times 10^{-3}$ and $3 \times 10^{-3}$ for sample $\mathrm{A}$ 
at room temperature, as revealed by high resolution XRD $\omega-2 \theta$ measurements of multiple on- and off-axis reflections. The unstrained bandgap of cubic $\mathrm{GaN}$ is $3.30 \mathrm{eV}$ at $10 \mathrm{~K}[21]$; therefore the bandgap of these samples is reduced to between $3.26 \mathrm{eV}$ and $3.27 \mathrm{eV}$, which corresponds well with the absorption edge in the photoluminescenceexcitation spectra. In sample $\mathrm{B}$, the $\mathrm{D}^{0} \mathrm{X}$ peak energy is $10 \mathrm{meV}$ higher than sample A, which could be caused by a reduction in tensile strain towards the top of sample $B$.

The second peak in the spectra in Figure 2, centered at $3.15 \mathrm{eV}$ and $3.13 \mathrm{eV}$ for samples $\mathrm{A}$ and $\mathrm{B}$ also correspond to an absorption edge in Figure 3 at the cubic GaN bandgap, but are not present in the PL spectra above $80 \mathrm{~K}$. As the excitation power is increased, the peak intensity increases sublinearly and blueshifts by $0.04 \mathrm{eV}$, as shown in Figure 6. The decay transients for this emission are not mono-exponential, as shown in Fig. 5, and faster decays are observed at higher energies, as in Figure 7. These behaviours are indicative of donor-acceptor recombination (DAP) [24].

The DAP peak energy at $10 \mathrm{Wcm}^{-2}$ is $0.02 \mathrm{eV}$ higher in sample A than B in Figure 2. If this is corrected for the relative bandgaps of the two samples the difference is increased to $0.03 \mathrm{eV}$. In addition, the intensity of the DAP peak relative to the $\mathrm{D}^{0} \mathrm{X}$ is also reduced in sample $\mathrm{B}$. This is tentatively ascribed to a reduced density of the associated donor and/or acceptor states.

Both samples A and B present a low intensity emission band centered at $2.00 \mathrm{eV}$ in Figure 2, with FWHM of approximately $400 \mathrm{meV}$. This is tentatively assigned to the YL, based on data reported previously fo hexagonal GaN [22]. The YL is less dominant in sample A, which suggests there may be a reduced density of carbon and oxygen impurities and gallium vacancies to which the YL is typically attributed [29,30].

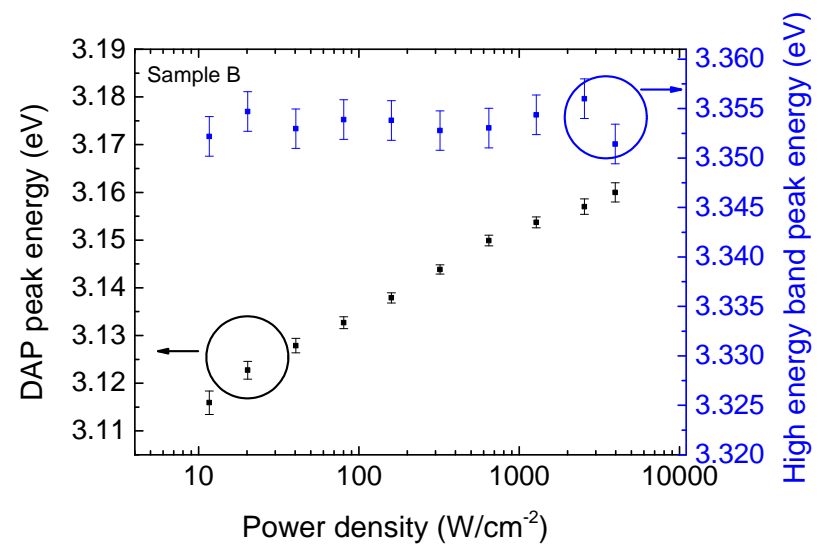

Figure 6 Power dependence of the peak energies for the DAP emission (black) and high energy band (blue) in the PL spectra of sample B in Figure 2.

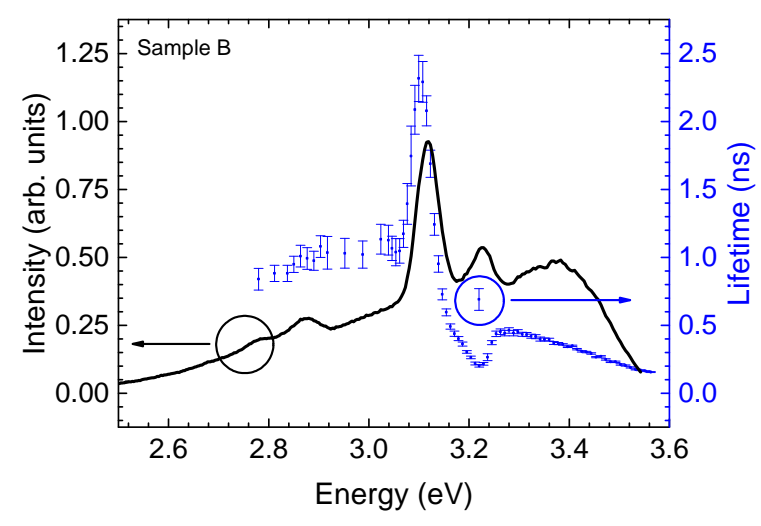

Figure 7 1/e lifetimes (blue) of PL decays, such as those in Figure 5 , at $10 \mathrm{~K}$. The $10 \mathrm{~K}$ PL spectrum (black) for sample B, measured under pulsed excitation. The circled point is the lifetime of the low intensity background of the $\mathrm{D}^{0} \mathrm{X}$ decay.

An additional low intensity band is present near $3.00 \mathrm{eV}$ in sample A and B. Photoluminescence-excitation measurements in Figure 3 show an absorption edge around $3.27 \mathrm{eV}$, which suggests that this emission is associated with the cubic GaN. This emission is typically attributed to various DAP and free-to-bound recombination pathways and phonon replicas in cubic GaN with unknown origins [12,23-25] and is comparable in intensity between samples $\mathrm{A}$ and $\mathrm{B}$.

A conventional assessment of the crystal quality is given by the FWHM of the $\mathrm{D}^{0} \mathrm{X}$ peak and the $\omega$-broadening of the $002 \mathrm{X}$-ray reflection, which in these samples, reduces from $47 \mathrm{meV}$ and $38^{\prime}$ in sample A to $33 \mathrm{meV}$ and $30^{\prime}$ in sample B respectively. This suggests that the local quality of regions of cubic material is improved for sample B. However, this corresponds with the introduction of an emission band, with a peak emission energy of $3.40 \mathrm{eV}$ and a FWHM of $190 \mathrm{meV}$, in the PL spectrum of sample B. Since this feature is not present in sample A, it is reasonable to conclude that it is a result of introducing the AlN interlayer into the crystal.

Defect luminescence within the AIN interlayer can be ruled out as the cause of this emission band since the layer is only 10 thick, and the excitation energy is below the bandgap energy of the AIN (6 eV). Luminescence in this region of the spectrum has previously been attributed to hexagonal GaN $[8,9,11,12,23]$, although significant emission above the recombination energy of excitons in hexagonal $\mathrm{GaN}$ has not been reported. It is therefore likely that the hexagonal $\mathrm{GaN}$, as either inclusions or stacking faults in the TEM, is responsible for the emission band.

The photoluminescence-excitation spectra for the $3.40 \mathrm{eV}$ band are in Figure 3, which show a shallow absorption edge starting between $3.60 \mathrm{eV}$ and $3.70 \mathrm{eV}$. This 


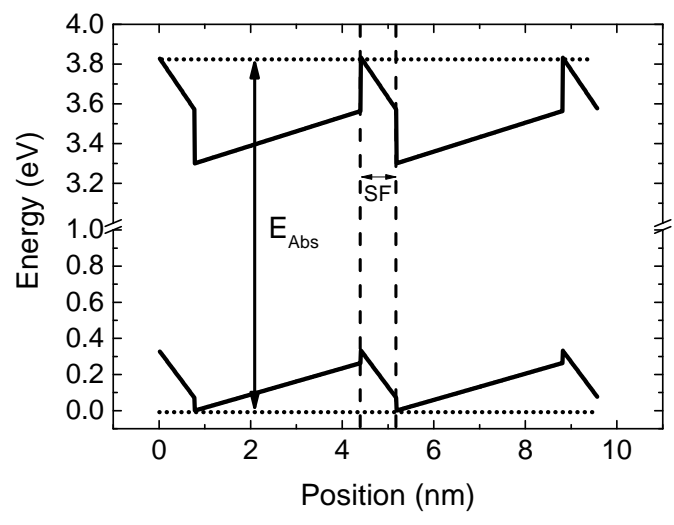

Figure 8 Band alignment adjacent to stacking faults in the cubic $\mathrm{GaN}$, along the hexagonal [0001] direction, assuming valence and conduction band offsets of 70 and $270 \mathrm{meV}$ [34] and a spontaneous polarisation of $-0.034 \mathrm{Cm}^{-2}$ [21]. The electric field has been calculated using equations devised by Bernardini et al. [35] for multiple quantum well systems.

is not consistent with the bandgap of hexagonal GaN. In addition, the onset of the absorption edge shifts by approximately $0.05 \mathrm{eV}$ when detecting at different energies across the emission band. The emission extends to energies as low as $3.18 \mathrm{eV}$, which is evident as a comparable absorption edge is observed in the photoluminescence-excitation spectrum measured at this energy. This behaviour suggests that the emission does not originate from the hexagonal inclusions seen in the TEM, for which we might expect a narrower peak, similar to the exciton from sample $\mathrm{C}$ in Figure 2. This could be due to exciton diffusion out of the inclusions, since the diffusion length in $\mathrm{GaN}$ has been measured to be similar to the size of the inclusions [19].

As the excitation density is increased, the intensity of this band increases linearly and the peak energy is unchanged, as shown in Figure 6. The FWHM is also independent of the excitation density. There is therefore no indication of any saturation effects. Futhermore, PL time decay measurements in Figure 5 indicate that the decay transients are monoexponential and fast, with lifetimes around $0.20 \mathrm{~ns}$ at the highest emission energies. At reduced energies, the lifetime increases, reaching $0.40 \mathrm{~ns}$ at $3.30 \mathrm{eV}$ in Figure 7. At further reduced energies, the lifetime reduces since the $\mathrm{D}^{0} \mathrm{X}$ becomes the dominant component in the spectrum. However, there remains a lower intensity, longer lifetime monoexponential component to the decay. The lifetime of this component can be found via a biexponential fit to the decay, yielding $0.68 \mathrm{~ns}$. This is assigned to the high energy band, since the lifetime of this decay is consistent with the approximately linear trend for the other decays in this band.
Adjacent to SFs, a type-II QW-like potential profile is formed [31-34], as shown in Figure 8. Electric fields are present due to differences in the spontaneous polarisation fields of the two crystal phases [21]. Recombination will occur with electrons, confined within the cubic $\mathrm{GaN}$ by the electric fields and SF barriers, and holes, confined in a triangular QW by the electric fields. More densely packed stacking faults will result in a narrower confinement region for the electrons, which will increase the confinement energy and hence the recombination energy. It is clear from Figure 8 that this could occur above $3.50 \mathrm{eV}$, the hexagonal GaN bandgap, and may therefore account for the PL in Figure 2. The absorption edge would occur due to a reduction in the density of states as the energy falls below $E_{A b s}$, as indicated in Figure 8. This energy is a few 100 meV larger than the bandgap of hexagonal GaN and may explain the absorption edge energies in Figure 3. This band alignment spatially separates the carriers and would result in a PL decay time that reduces as the recombination energy increases, consistent with observations in Figure 7. Therefore this densely packed SF picture can qualitatively account for the observations of the high energy band.

4 Summary Two samples of GaN grown by MOCVD upon $3 \mathrm{C}-\mathrm{SiC} / \mathrm{Si}$ (001) substrates were studied to investigate the luminescence properties of a cubic and a mixed phase layer of GaN, samples A and B respectiely. These properties were compared with a c-plane hexagonal GaNon-Sapphire sample, sample C. Photoluminescence-excitation measurements at $10 \mathrm{~K}$ illustrated that the majority of emission features below $3.27 \mathrm{eV}$ were associated with cubic GaN. Temperature and power dependent PL measurements, along with PL time decays, were used to identify the origins of the main PL features: a dominant $\mathrm{D}^{0} \mathrm{X}$ peak between $3.23 \mathrm{eV}$ and $3.24 \mathrm{eV}$, followed by a DAP peak between $3.15 \mathrm{eV}$ and $3.13 \mathrm{eV}$ and the $\mathrm{YL}$ at $2.00 \mathrm{eV}$. A comparison of the peak $\mathrm{D}^{0} \mathrm{X}$ energy and absorption edge between these samples and literature lead to an estimated strain-induced cubic GaN bandgap between $3.26 \mathrm{eV}$ and $3.27 \mathrm{eV}$.

The DAP emission for sample B is less intense than that in sample A and the peak energy is lower for equivalent excitation powers, which we tentatively attribute to a lower density of donor and/or acceptor impurity states in this sample. In contrast, the YL is more intense in sample B.

The PL spectra indicate that sample $B$ has a reduced $\mathrm{D}^{0} \mathrm{X}$ FWHM compared to sample A and a $0.01 \mathrm{eV}$ larger bandgap. This suggests that the local tensile strain of the cubic material has been partially relaxed. An emission band with a peak energy at $3.40 \mathrm{eV}$ and a FWHM of $190 \mathrm{meV}$ is also observed for sample B. This emission band extends to energies up to $3.60 \mathrm{eV}$, above the hexagonal $\mathrm{GaN}$ bandgap. Photoluminescence-excitation 
measurements show a shallow absorption edge below approximately $3.70 \mathrm{eV}$, which indicates this cannot be due to absorption in phase-pure cubic or hexagonal GaN. The PL decays for this emission are monoexponential and fast, with lifetimes around $0.30 \mathrm{~ns}$, decreasing at higher energies. This may be a result of quantum confinement at bunches of stacking faults.

Acknowledgements This was work funded by EPSRC under grants EP/M010627/1 and EP/N01202X/1, and Innovate UK under grant 56917-383420. Additional research data supporting this publication are available from the University of Manchester repository at DOI: $10.15127 / 1.305132$.

\section{References}

[1] S. F. Chichibu, M. Sugiyama, T. Onuma, T. Kitamura, H. Nakanishi, T. Kuroda, A. Tackeuchi, T. Sota, Y. Ishida, and H. Okumura, Appl. Phys. Lett. 79(26), 4319 (2001).

[2] S. Li, J. Schormann, D. J. As, and K. Lischka, Appl. Phys. Lett. 90(7), 071903 (2007).

[3] D. J. As, Microelectronics J. 40(2), 204 (2009).

[4] C. J. M. Stark, T. Detchprohm, S. C. Lee, Y. B. Jiang, S. R. J. Brueck, and C. Wetzel, Appl. Phys. Lett. 103(23), 232107 (2013).

[5] M. T. Durniak, A. S. Bross, D. Elsaesser, A. Chaudhuri, M. L. Smith, A. A. Allerman, S.C. Lee, S. R. J. Brueck, and C. Wetzel, Adv. Electron. Mater. 2(3), 1500327 (2016).

[6] C. H. Wei, Z. Y. Xie, L. Y. Li, Q. M. Yu, and J. H. Edgar, J. Electron. Mater. 29(3), 317 (2000).

[7] G. Feuillet, F. Widmann, B. Daudin, J. Schuler, M. Arlery, J. L. Rouvière, N. Pelekanos, and O. Briot, Mater. Sci. Eng. B 50(1), 233 (1997)

[8] B. Daudin, G. Feuillet, J. Hubner, Y. Samson, F. Widmann, A. Philippe, C. Bru-Chevallier, G. Guillot, E. Bustarret, G. Bentoumi, and A. Deneuville, J. Appl. Phys. 84(4), 2295 (1998).

[9] A. Philippe, C. Bru-Chevallier, M. Vernay, G. Guillot, J. Hü Bner, B. Daudin, and G. Feuillet, Mater. Sci. Eng. B 59(1), 168 (1999).

[10] D. Wang, Y. Hiroyama, M. Tamura, M. Ichikawa, and S. Yoshida, J. Cryst. Growth 220(3), 204 (2000).

[11] E. Martinez-Guerrero, B. Daudin, G. Feuillet, H. Mariette, Y. Genuist, S. Fanget, A. Philippe, C. Dubois, C. BruChevallier, G. Guillot, P. Aboughe Nze, T. Chassagne, Y. Monteil, H. Gamez-Cuatzin, and J. Tardy, Mater. Sci. Eng. B 82(1), 59 (2001).

[12] M. Feneberg, M. Röppischer, C. Cobet, N. Esser, J. Schörmann, T. Schupp, D. J. As, F. Hörich, J. Bläsing, A. Krost, and R. Goldhahn, Phys. Rev. B 85(15), 155207 (2012).

[13] S. Kako, M. Holmes, S. Sergent, M. Bürger, D. J. As, and Y. Arakawa, Appl. Phys. Lett. 104(1), 011101 (2014).

[14] T. Wecker, G. Callsen, A. Hoffmann, D. Reuter, and D. J. As, Jpn. J. Appl. Phys. 55(5S), 05FG01 (2016).

[15] V. Siklitsky, New Semiconductor Materials, Characteristics and Properties. Accessed: 2017-01-03. http://www.ioffe.ru/SVA/NSM/Semicond/index.html.

[16] A. Dadgar, M. Poschenrieder, J. Blasing, K. Fehse, A. Diez, and A. Krost, Appl. Phys. Lett. 80(20), 3670 (2002).
[17] C. C. Huang, F. J. Xu, J. Song, Z. Y. Xu, J. M. Wang, R. Zhu, G. Chen, X. Q. Wang, Z. J. Yang, B. Shen, X. S. Chen, and W. Lu, J. Appl. Phys. 111(1), 016105 (2012).

[18] J. F. Muth, J. H. Lee, I. K. Shmagin, R. M. Kolbas, H. C. Casey, B.P. Keller, U.K. Mishra, and S.P. DenBaars, Appl. Phys. Lett. 71(18), 2572 (1997).

[19] M. Hocker, P. Maier, L. Jerg, I. Tischer, G. Neusser, C. Kranz, M. Pristovsek, C. J. Humphreys, R. A. R. Leute, D. Heinz, O. Rettig, F. Scholz, and K. Thonke, J. Appl. Phys. 120(8), 085703 (2016).

[20] D. M. Graham, A. Soltani-Vala, P. Dawson, M. J. Godfrey, T. M. Smeeton, J. S. Barnard, M. J. Kappers, C. J. Humphreys, and E. J. Thrush, J. Appl. Phys. 97(10), 103508 (2005).

[21] I. Vurgaftman and J. R. Meyer, J. Appl. Phys. 94(6), 3675 (2003).

[22] M. A. Reshchikov and H. Morkoç, J. Appl. Phys. 97(6), 061301 (2005).

[23] H. Okumura, K. Ohta, G. Feuillet, K. Balakrishnan, S. Chichibu, H. Hamaguchi, P. Hacke, and S. Yoshida, J. Cryst. Growth 178(1-2), 113 (1997).

[24] J. Wu, H. Yaguchi, K. Onabe, R. Ito, and Y. Shiraki, Appl. Phys. Lett. 71(15), 2067 (1997).

[25] D. Xu, H. Yang, J. B. Li, D. G. Zhao, S. F. Li, S. M. Zhuang, R. H. Wu, Y. Chen, and G. H. Li, Appl. Phys. Lett. 76(21), 3025 (2000).

[26] J. Fernandez, O. Noriega, J. Soares, F. Cerdeira, E. Meneses, J. Leite, D. As, D. Schikora, and K. Lischka, Solid State Commun. 125(3-4), 205 (2003).

[27] J. Renard, G. Tourbot, D. Sam-Giao, C. Bougerol, B. Daudin, and B. Gayral, Appl. Phys. Lett. 97(8), 081910 (2010).

[28] S. Waheeda, N. Zainal, Z. Hassan, S. Novikov, A. Akimov, and A. Kent, Appl. Surf. Sci. 317(1), 1010 (2014).

[29] J. L. Lyons, A. Janotti, and C. G. Van de Walle, Appl. Phys. Lett. 97(15), 152108 (2010).

[30] M. A. Reshchikov, J. D. McNamara, F. Zhang, M. Monavarian, A. Usikov, H. Helava, Y. Makarov, and H. Morkoç, Phys. Rev. B 94(3), 035201 (2016).

[31] G. Jacopin, L. Rigutti, L. Largeau, F. Fortuna, F. Furtmayr, F. H. Julien, M. Eickhoff, and M. Tchernycheva, J. Appl. Phys. 110(6), 064313 (2011).

[32] P. Corfdir and P. Lefebvre, J. Appl. Phys. 112(5), 053512 (2012).

[33] M. Forsberg, A. Serban, I. Poenaru, C. L. Hsiao, M. Junaid, J. Birch, and G. Pozina, Nanotechnology 26(35), 355203 (2015).

[34] C. Stampfl and C. G. Van de Walle, Phys. Rev. B 57(24), R15052 (1998).

[35] F. Bernardini and V. Fiorentini , Phys. status solidi (b) 216, 391 (199). 